Editorial

\title{
Athletic Incontinence: Proposal of a New Term for a New Woman
}

\section{Incontinência de atletas: proposta de novo termo para uma nova mulher}

\author{
Maíta Poli de Araujo ${ }^{1}$ Marair Gracio Ferreira Sartori ${ }^{1}$ Manoel João Batista Castello Girão ${ }^{1}$ \\ ${ }^{1}$ Gynecology and Obstetrics Departament, Escola Paulista de \\ Medicina, Universidade Federal de São Paulo, São Paulo, SP, Brazil
}

Rev Bras Ginecol Obstet 2017;39:441-442.

In 1896, Baron Pierre de Coubertin inaugurated the first modern era Olympic Games. At that time, women could not participate in the competitions, as sports in general were considered dangerous for women's health. At the Paris Olympics (1900), of the 997 enrolled athletes, 22 were women who competed in sailing, tennis and golf. ${ }^{1}$ Women's participation increased considerably, and in the 2016 Olympic Games, which were held in the city of Rio de Janeiro, almost half of the athletes were women. ${ }^{2}$

However, the "slogan" proposed by Baron de Coubertin during the creation of the International Olympic Committee, "Citius, Altius, Fortius" (faster, higher, stronger), has caused

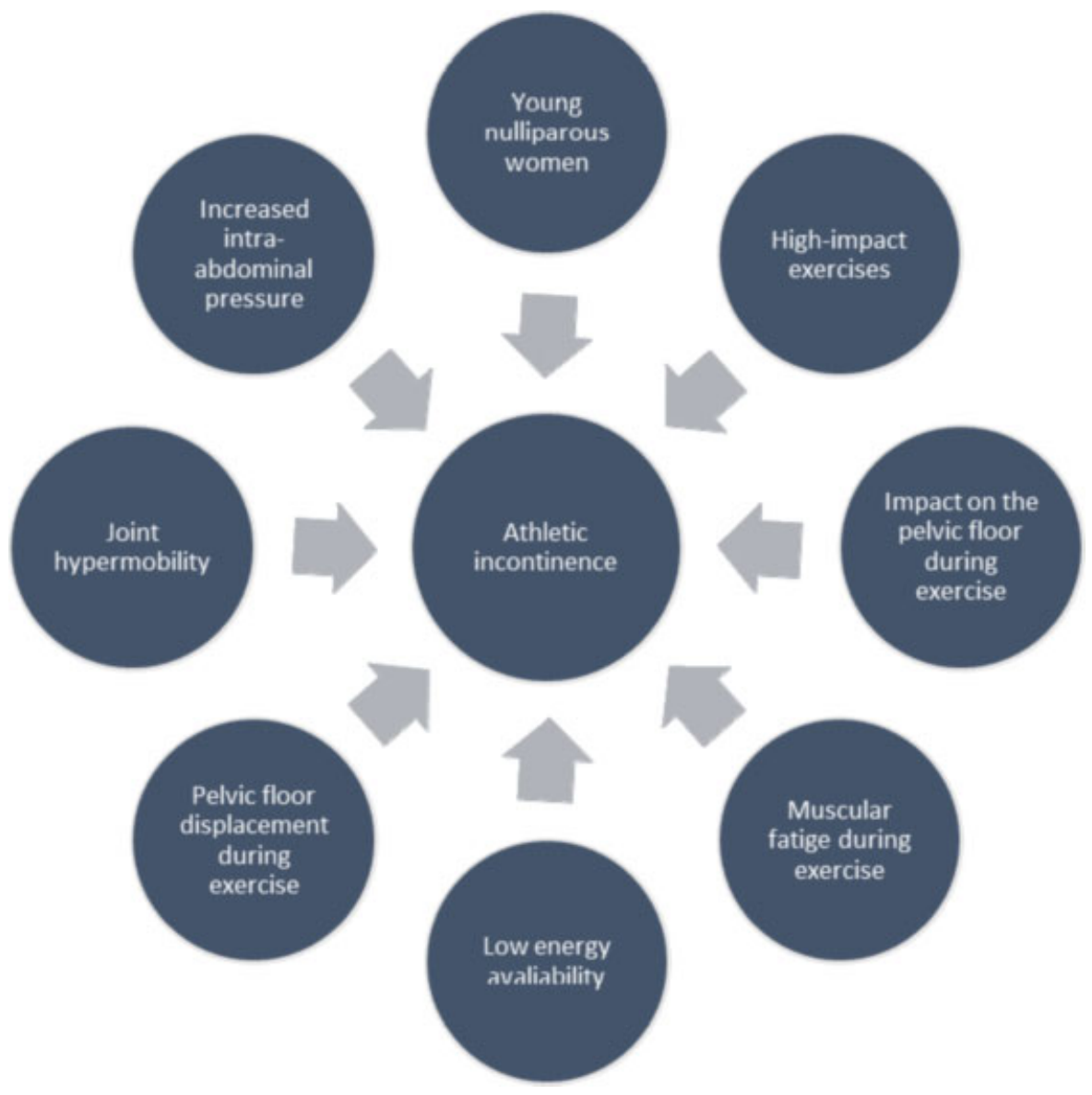

Fig. 1 Physiopathology of athletic incontinence.

Address for correspondence Maíta Poli de Araujo, MD, PhD, DOI https://doi.org/ Rua Loefgrenn, 1570, 01403-003, ISSN 0100-7203. Vila Clementino, São Paulo, SP, Brasil (e-mail: dramaita@gmail.com).
Copyright (e 2017 by Thieme Revinter Publicações Ltda, Rio de Janeiro, Brazil 
numerous problems to the health of female athletes. ${ }^{3}$ Irregular or absent menstrual cycles, inadequate eating behaviors, muscular injuries, stress fractures and pelvic floor dysfunctions have been increasing among physically active women. ${ }^{4}$

Women who practice high-impact, high-intensity exercises are eight times more likely to suffer from involuntary urine loss when compared with sedentary women in the same age group. ${ }^{5}$ The sports at risk for this condition include acrobatic trampoline (trampoline), long distance running, volleyball and basketball. ${ }^{6}$ Unlike stress urinary incontinence, in which urine leakage occurs during coughing, sneezing, or lifting weight, these young women report the symptom only during exercise. ${ }^{7}$ Therefore, the term athletic incontinence would be the most appropriate for these patients who complain only during physical exercise and do not lose urine during their other activities.

Athletic incontinence affects young, nulliparous women with an adequate body mass index. ${ }^{8}$ These women do not have the classic risk factors for pelvic floor dysfunction, such as age, parity and obesity. ${ }^{9}$

The pathophysiology of athletic incontinence is complex, and includes biomechanical factors (impact on and displacement of the pelvic floor during exercise), increased intraabdominal pressure, decreased energy availability (a condition that interferes with the hypothalamic control of the menstrual cycle, leading to hypoestrogenism), and joint hypermobility (-Fig. 1) ${ }^{7,10}$

The urodynamic exam of these patients is not able to reproduce the situation in which urine leakage occurs, and the conventional pad test is flawed. ${ }^{11}$ Pelvic floor muscle training may improve athletic incontinence, but the specificity of each modality should be adjusted. ${ }^{12}$ Many of these physically active women use vaginal devices such as tampons or pessaries to minimize urine loss. ${ }^{13}$ Restrictive diets and the use of licit and illicit supplements are common, and should be evaluated before the treatment. ${ }^{7}$

We conclude, therefore, that athletic incontinence is a specific condition that occurs in young and nulliparous women only while they are practicing sports. For this reason, it should be evaluated and treated differently from the other categories of urinary incontinence.
Conflicts of Interest

The authors have no conflicts of interest to disclose.

\section{References}

1 O'Brien M, Robertson A. Women and sport. Scott Med J 2010; 55(02):25-28

2 Church H, Murdoch-Eaton D, Patel R, Sandars J. What can medical educators learn from the Rio 2016 Olympic Games? Med Teach 2017;39(06):665-666

3 Seiler S. Same Citius, Altius, Fortius...more women, crashes, and McTwists? Int J Sports Physiol Perform 2014;9(01):122-127

4 Joy EA, Van Hala S, Cooper L. Health-related concerns of the female athlete: a lifespan approach. Am Fam Physician 2009;79(06): 489-495

5 Almeida MB, Barra AA, Saltiel F, Silva-Filho AL, Fonseca AM, Figueiredo EM. Urinary incontinence and other pelvic floor dysfunctions in female athletes in Brazil: A cross-sectional study. Scand J Med Sci Sports 2016;26(09):1109-1116

6 Fozzatti C, Riccetto C, Herrmann V, et al. Prevalence study of stress urinary incontinence in women who perform high-impact exercises. Int Urogynecol J Pelvic Floor Dysfunct 2012;23(12):1687-1691

7 Araújo MP, Oliveira Ed, Zucchi EV, Trevisani VF, Girão MJ, Sartori MG. [The relationship between urinary incontinence and eating disorders in female long-distance runners]. Rev Assoc Med Bras (1992) 2008;54(02):146-149

8 Eliasson K, Edner A, Mattsson E. Urinary incontinence in very young and mostly nulliparous women with a history of regular organised high-impact trampoline training: occurrence and risk factors. Int Urogynecol J Pelvic Floor Dysfunct 2008;19(05):687-696

9 Hagovska M, Švihra J, Buková A, et al. Prevalence of urinary incontinence in females performing high-impact exercises. Int J Sports Med 2017;38(03):210-216

10 Dias N, Peng Y, Khavari R, et al. Pelvic floor dynamics during highimpact athletic activities: A computational modeling study. Clin Biomech (Bristol, Avon) 2017;41:20-27

11 Barton A, Serrao C, Thompson J, Briffa K. Transabdominal ultrasound to assess pelvic floor muscle performance during abdominal curl in exercising women. Int Urogynecol J Pelvic Floor Dysfunct 2015;26(12):1789-1795

12 Da Roza T, de Araujo MP, Viana R, et al. Pelvic floor muscle training to improve urinary incontinence in young, nulliparous sport students: a pilot study. Int Urogynecol J Pelvic Floor Dysfunct 2012;23(08):1069-1073

13 Glavind K. Use of a vaginal sponge during aerobic exercises in patients with stress urinary incontinence. Int Urogynecol J Pelvic Floor Dysfunct 1997;8(06):351-353 